State of the art lectures 


\title{
Advances in the genotyping of thrombosis genetic risk factors: clinical and laboratory implications
}

\author{
José Manuel Cabeda ${ }^{1,2,3}$, Mónica Pereira ${ }^{1}, J^{\prime}$ osé Miguel Oliveira', Alexandra Estevinho', \\ Irene Pereira' ${ }^{2}$, Sara Morais ${ }^{2}$, Benvindo Justiça ${ }^{2}$, Manuel Campos ${ }^{2}$ \\ ${ }^{1}$ Molecular Biology Unit and ${ }^{2}$ Clinical Haematology, Santo António General Hospital, Porto, Portugal; ${ }^{3}$ Faculdade de Ciências da Saúde-Universidade \\ Fernando Pessoa, Porto, Portugal
}

\begin{abstract}
Since FV-Leiden polymorphism was first described in 1994, a growing number of polymorphic loci have been identified in association with increased genetic risk for thrombophilia. Often however, these risk factors have been studied in isolation of the remaining known phenotype linked polymorphisms. This fact has, at least in part, been justified by the laborious techniques traditionally used in the genotyping studies, as well as its relatively high costs. Another major problem concerning these studies has been the non-negligible incidence of dubious genotypes, resulting from the manual, labour intensive techniques applied, and their sometimes difficult to read output's. These difficulties have also hampered the widespread use of genotyping data in the clinical assessment of the genetic risk levels both in patients and their relatives, leaving some clinicians less than convinced about its clinical usefulness.

Recently however, the introduction of new genetic techniques in the clinical genetics laboratory has started to change this picture. Most notably, the advent of Realtime-PCR has brought the possibility of genotyping patients and controls at a large scale, with increased specificity, automation and speed. Moreover, the use of these techniques in the clinical genetics setting has not only increased the quality of the results, but most
\end{abstract}

importantly has also increased our capability of answering questions at a deeper level. Among the new questions that can now be answered without increased costs and uncertainty is the study of the association of genetic risk factors in thrombophilia. Our results show that indeed even common polymorphic loci may increase our ability to further discriminate the genetic thrombosis risk of individual patients and relatives.

It must however be noted that the innovation level in the clinical genetics lab is just starting to grow. In fact we haven't even started to experience the advantages brought about by the genome program, and its massive identification of SNP's. The technology to test these is also presently being refined, and is expected to go from research to the clinical lab in the near future. Only then, can we expect to define with high certainty the combined genetic risks for such complex pathologies as the thrombophilias.

Copyright $\odot 2002$ S. Karger AG. Basel

\section{KARGER \\ Fax +41613061234 \\ E-Mail karger@karger.ch}

www.karger.com (c) 2002 S. Karger AG. Basel

$1424-8832 / 02 / 0326-0235 \$ 18.50 / 0$

Accessibile online at: www.karger.com/journals/pht
Prof. Manuel Campos

Servicio de Hemotologia - Hospital de Santo Antonio

Largo Prof. Abel Salazar - 400 Porto, Portugal

tel. 00351-226004808

E-Mail: mcampos@teleweb.pt or jcabeda@mail.telepac.pt 


\section{Materials and methods}

A total of 863 individuals (226 healthy blood donors, 253 arterial thrombosis patients and 384 venous thrombosis patients were included in the study. Arterial thrombosis events included 16 patients with ischemic thrombosis, 157 with stroke, 59 with myocardial infarction, 9 with retinal artery thrombosis, 6 with pulmonary artery thrombosis and 6 with other arterial thrombosis. Venous thrombosis events included 13 patients with venous cerebral thrombosis, 338 with deep venous thrombosis, 2 with portal vein thrombosis, and 31 other venous thrombosis events.

Factor V-Leiden and Prothrombin G20210A polymorphisms were tested by Real-time-PCR in the LightCycler (Roche, Germany) using commercially available kits from the same supplier. Previously, Factor V-Leiden and Prothrombin G20210A had been tested by PCR-ASO using kits from Vienna Labs (Austria). PCR-RFLP was also used in the past to test for Factor-V-Leiden using a previously published protocol (1). Methylenetetrahydrofolate Reductase (MTHFR) C677T polymorphism was tested using previously described primers and probes (2) with the DNA FastStart Hybridization probes kit (Roche) optimised at $2.5 \mathrm{mM} \mathrm{McCl} 2$ and the following thermal cycling protocol: Enzime activation at $94^{\circ} \mathrm{C}$ for $8 \mathrm{~min}$ utes followed by 40 round of amplification consisting on denaturation at $94^{\circ} \mathrm{C}$ for 0 seconds, annealing at $55^{\circ} \mathrm{C}$ for 10 seconds and polymerisation at $72^{\circ} \mathrm{C}$ for 15 seconds. Acquisition was performed during the annealing step.The melting profile included an initial denaturation at $94^{\circ} \mathrm{C}$ for 0 seconds, a stabilization at $40^{\circ} \mathrm{C}$ for 5 seconds, and the melting step with $80^{\circ} \mathrm{C}$ target temperature and stepwise acquisition at $0.6^{\circ} \mathrm{C} /$ second.

Serum levels of Protein C, Protein S and Antithrombin III were assayed using the respective IL test on the ACL 9000 system (Instrumentation Laboratory, USA), as recommended by the manufacturer.

Comparison of polymorphism frequencies between groups was done by the chi square test using the Statistica for Windows software package (Statsoft).

\section{Introduction and results}

Thrombosis is a haematological disorder with variable interacting causes that range from acquired to hereditary risk factors (3-6). Over the last decade an increasing number of genetic polymorphic markers associated with thrombosis have been described - a simple search on NCBI nucleotide database (www.ncbi.nih.gov) with the words "thrombosis AND Homo sapiens" returned at writing time 102 different entries, corresponding to a total of 39 different genes. This list however does not include some genes with polymorphisms that represent weak risk factors for thrombosis such as the MTHFR gene. In fact, a quick browse of the literature has allowed us to generate a list of another 20 loci (3-7). In addition to coagulation risk factors, some immunological related polymorphic loci may also mediate thrombosis risk, by modulating the presence of auto-antibodies that in turn modulate the plasma levels of coagulation factors. Therefore, this already long list of genetic risk factors for thrombosis should be regarded as a still incomplete and evolving list.

Not only has this list of polymorphic loci modulating the risk of thrombosis been growing, as the technical tools to study them have been changing dramatically in the same period. These improvements have enabled clinically useful genetic testing for the diagnosis of diverse pathological situations such as infectious, oncologic, and genetic diseases be them of a monogenic or a multifactorial trait such as thrombosis.

The technical genotyping advances, although greatly increasing speed, accuracy and volume, have also increased the range of techniques used at any single moment in diverse labs to test for the same parameter. This, in turn, has increased the possibility that different laboratories testing the same sample would return divergent results.

Genotyping experiments have evolved from the PCR-RFLP techniques from late 1990's to ARMS-PCR, PCR-ASO, and more recently Real-Time-PCR with melting profile analysis. Although the first techniques used are less expensive and easier to implement in a molecular biology lab, they are also more prone to error, laborious, and far less convenient when a large number of samples has to be studied. Despite these inconvenients, economical issues still make them a convenient choice for many labs.

One of PCR-RFLP's most serious problems affecting result fidelity is the occurrence of incomplete reactions, which should be checked, using an internal universal restriction site. However, this internal control is not always possible to implement, leaving some room for result uncertainty.

ARMS-PCR is prone to false negative amplification reactions caused by sample-to-sample variations in inhibitor concentrations. For this reason, an internal control is mandatory in this procedure, and can only be substituted by the universal use of an extra inhibition control reaction for each of the amplification reactions.

PCR-ASO is a useful and widely used technique due to the possibility of automation in the microtiter plate based forms, using the common and largely available ELISA automation equipments. However, automation cannot by itself prevent variations in PCR kinetics between different reactions (or between different DNA templates in the same reaction). Since genotyping usually relies on the comparison of end-point signal intensity, these variations can significantly influence the results. In fact, in our lab, we have found that inter-reaction variability can vary on average 13-26\% (ranging from 0 to $173 \%$ ). In order to control this variation we have implemented as routine, the use of triplicates for any genotyping experiment 
Table 1. Frequency of Wild-Type and mutated alleles in patients and controls

\begin{tabular}{|c|c|c|c|c|c|c|c|}
\hline \multirow[b]{2}{*}{ Genotype/phenotype a) } & \multirow[b]{2}{*}{ Allele ${ }^{b}$} & \multirow[b]{2}{*}{ Controls } & \multirow[b]{2}{*}{$\mathrm{ATc}^{\mathrm{b})}$} & \multirow[b]{2}{*}{$\mathrm{VT}^{\mathrm{c})}$} & \multicolumn{3}{|c|}{ Significance value } \\
\hline & & & & & $\mathrm{AT} / \mathrm{VT}^{\mathrm{c}}$ & $\mathrm{C} / \mathrm{AT}^{\mathrm{c})}$ & $\mathrm{C} / \mathrm{VT}^{\mathrm{c})}$ \\
\hline Factor V-Leiden & WT & 221 & 242 & 327 & $<0.00001$ & n.s. & $<0.00001$ \\
\hline & M & 5 & 6 & 53 & & & \\
\hline PTH & WT & 214 & 237 & 347 & $<0.0236$ & n.s. & n.s. \\
\hline MTHFR & $\begin{array}{l}\text { M } \\
\text { WT }\end{array}$ & $\begin{array}{l}12 \\
95\end{array}$ & $\begin{array}{l}9 \\
111\end{array}$ & $\begin{array}{l}31 \\
142\end{array}$ & n.s. & n.s. & n.s. \\
\hline ATIII & $\begin{array}{l}\mathrm{M} \\
\mathrm{N} \\
\text { Low }\end{array}$ & $\begin{array}{l}119 \\
30 \\
0\end{array}$ & $\begin{array}{l}132 \\
221 \\
1\end{array}$ & $\begin{array}{l}228 \\
316 \\
7\end{array}$ & n.s. & n.s. & n.s. \\
\hline Prot. C & $\begin{array}{l}\mathrm{N} \\
\text { Low }\end{array}$ & $\begin{array}{l}30 \\
0\end{array}$ & $\begin{array}{l}211 \\
5\end{array}$ & $\begin{array}{l}293 \\
26\end{array}$ & $<0.0046$ & n.s. & n.s. \\
\hline Prot. S & $\begin{array}{l}\mathrm{N} \\
\text { Low }\end{array}$ & $\begin{array}{l}30 \\
0\end{array}$ & $\begin{array}{l}202 \\
12\end{array}$ & $\begin{array}{l}289 \\
30\end{array}$ & n.s. & n.s. & n.s. \\
\hline
\end{tabular}

a) Factor V leiden, Prothrombin and MTHFR refer to the respective genotypes, whereas ATIII, Prot.C and Proc.S refer to the relative protein levels and are therefore phenotype determinations. All data available for each genotypic marker was included.

b) WT=Wild-type; $\mathrm{M}=$ mutated

c) AT=Arterial Thrombosis; VT=Venous thrombosis; $\mathrm{C}=$ control

by this method. As a result, from a total of 2840 reactions performed in triplicate (a total of 8520 assays for wild-type hybridisation probes and an equal amount with mutant hybridisation probes), we found 275 reactions $(9.7 \%)$ with at least one discordant genotyping result. Of these, only 10 $(0.4 \%)$ were completely discordant whereas the correct genotype of the remaining reactions could be deduced from the 2 concordant results. Nevertheless, if single reactions had been performed, which is common practice in most labs for economical reasons, up to $10 \%$ false results would be expected from this procedure.

The advent of Real-Time-PCR, in its several probe flavours

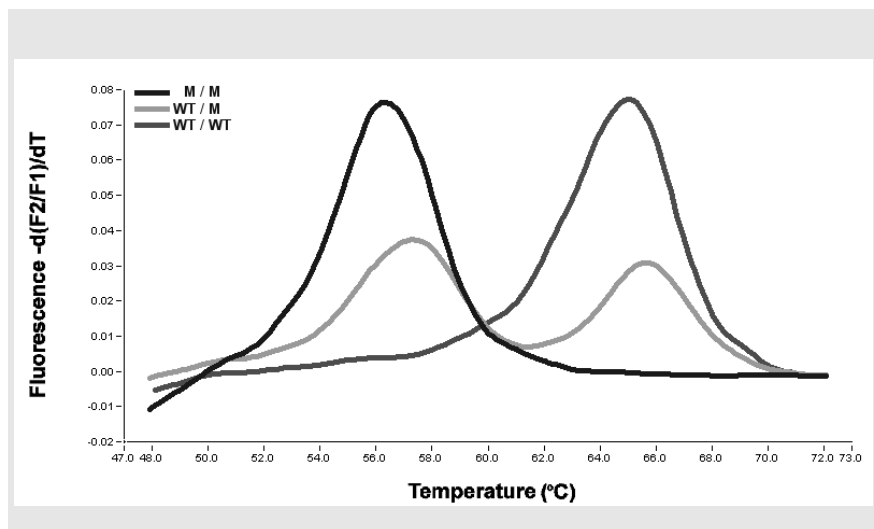

Fig. 1. Negative derivative of the melting profile for Factor $\mathrm{V}$ Leiden. Shown are the plots for homozygous wild-type (WT/WT), heterozygous (WT/M) and homozygous mutant (M/M) samples. Note that the observed peaks for the two alleles are well separated, making genotype discrimination simple and unambiguous. (mainly molecular beacons, Taqman, Eclipse and FRET) has allowed much faster amplification reactions (particularly with the Smartcycler[Cepheid] and most notably with LightCycler[Roche] technologies). Furthermore, because PCR product detection is a part of the PCR reaction, the overall time from PCR run to mutation detection can be greatly reduced (911). Moreover, since PCR detection does not require PCR product handling, nucleic acid contaminations attributable to PCR products are virtually eliminated.

Regardless of these advantages, Real-Time-PCR amplification also presents an additional feature, much valuable for genotype analysis - the opportunity to perform melting curve analysis, and therefore to determine the melting temperature of a specific nucleic acid sequence (10-11). The melting point determination is based on the fact that probe binding is a temperature and sequence dependent process. Thus, temperature ramping monitored by optical reading allows the machine to detect a drop in signal that will occur when the probe specifically reaches its sequence-dependent melting temperature. This variation in the fluorescence signal can be visualised by plotting the negative derivate of the fluorescence intensity. In this plot, a sudden decrease in signal strength is observed as a peak (fig.1), making possible a clear discrimination between homozygous wild-type, heterozygous and homozygous mutant samples (fig.1).

Over the last 2 years, we moved from microplate PCR-ASO hybridisation to a FRET based Real-Time-PCR procedure on the LightCycler (Roche, Germany) for the genotyping of Factor-V-Leiden, Prothrombin G20210A, and MTHFR C677T polymorphisms.

A total of 863 individuals (226 normal controls, 253 arteri- 
Table 2. Frequency of associated polymorphic risk markers of thrombosis

\begin{tabular}{|c|c|c|c|c|c|}
\hline & & & & & Significance level \\
\hline Genotype/phenotype a) & \# risk markers ${ }^{\mathrm{b})}$ & $\mathrm{C}^{\mathrm{c})}$ & $\mathrm{AT}^{\mathrm{c})}$ & $\mathrm{VT}^{\mathrm{c}}$ & $\mathrm{AT} / \mathrm{VT}^{\mathrm{c}}$ \\
\hline Factor V-Leiden & $\begin{array}{l}\leq 1 \\
>1\end{array}$ & $\begin{array}{c}40 \\
0\end{array}$ & $\begin{array}{c}204 \\
0\end{array}$ & $\begin{array}{c}303 \\
0\end{array}$ & \\
\hline$+\mathrm{PTH}$ & $\begin{array}{l}\leq 1 \\
>1\end{array}$ & $\begin{array}{c}40 \\
0\end{array}$ & $\begin{array}{c}203 \\
1\end{array}$ & $\begin{array}{c}300 \\
3\end{array}$ & n.s. \\
\hline + MTHFR & $\begin{array}{l}\leq 1 \\
>1\end{array}$ & $\begin{array}{c}33 \\
7\end{array}$ & $\begin{array}{c}174 \\
30\end{array}$ & $\begin{array}{c}233 \\
70\end{array}$ & $<0.0198$ \\
\hline + ATIII & $\begin{array}{l}\leq 1 \\
>1\end{array}$ & $\begin{array}{c}33 \\
7\end{array}$ & $\begin{array}{c}173 \\
31\end{array}$ & $\begin{array}{c}230 \\
73\end{array}$ & $<0.0150$ \\
\hline+ Prot. C & $\begin{array}{l}\leq 1 \\
>1\end{array}$ & $\begin{array}{c}33 \\
7\end{array}$ & $\begin{array}{c}171 \\
33\end{array}$ & $\begin{array}{c}222 \\
81\end{array}$ & $<0.0052$ \\
\hline + Prot. S & $\begin{array}{l}\leq 1 \\
>1\end{array}$ & $\begin{array}{c}33 \\
7\end{array}$ & $\begin{array}{c}166 \\
38\end{array}$ & $\begin{array}{c}208 \\
95\end{array}$ & $<0.0014$ \\
\hline
\end{tabular}

a) Factor V leiden, Prothrombin and MTHFR refer to the respective genotypes, whereas ATIII, Prot.C and Proc.S refer to the relative protein levels and are therefore phenotype determinations. Only data of individuals with all genotyping/phenotypic markers tested were included

b) Number of risk markers refers to the total number of risk markers found in each patient when considering only the genotypes/phenotypes from top of the table to each line. Note that for genotype markers each allele was considered one marker, thus an homozygous mutant individual would be considered to have 2 risk markers.

c) AT=Arterial Thrombosis; VT=Venous thrombosis; $\mathrm{C}=$ contro

al thrombosis patients [AT] and 384 venous thrombosis patients [VT]) were studied by genotyping procedures. In a subgroup of 547 individuals (40 normal controls, 204 AT and 303 VT patients) serum levels of Protein C, Protein S and Antithrombin III were also studied. As can be seen in table 1 the frequency of genetic polymorphisms/mutations found in the 863 individuals tested confirms that Factor V-Leiden is individually the genetic marker with the highest value in the discrimination of thrombotic genetic risk among venous thrombosis patients. Two other markers were found to be significantly different among venous and arterial thrombosis patients (Prothrombin G20210A, and reduced levels of protein C). In both cases, abnormalities were more frequent among venous thrombosis patients than among arterial thrombosis patients. In addition, none of the studied markers was found to individually show correlation to arterial thrombosis.

Although there is no significant correlation between most of the studied parameters alone and thrombosis, we were able to find an association between combined factors and increased thrombosis risk.

As can be seen in table 2, indeed when taken together, the studied risk factors are found to better discriminate between patients and controls, and between patient groups than when used alone. Interestingly, even modest thrombosis risk factors such as MTHFR C677T polymorphisms were found to contribute significantly to the global risk factor in the patient group. In fact, when the MTHFR polymorphism is only included in the last step (table 3), the increase in the number of patients identified by the inclusion of each additional factor is very small when compared to the observed when MTHFR is included (13 versus 78 in VT and 4 versus 34 in AT).
Therefore, our results show that even common polymorphisms cannot be excluded from investigation as they can be found to contribute significantly to the clarification of the global thrombosis genetic risk factor in any individual patient.

\section{Discussion}

The growing list of polymorphic loci relevantly influencing the genetic risk of thrombosis raises the discussion to the point of discriminating the most relevant loci for the study $(4,7)$. This is due to the economical and technical burden of studying an elevated number of genetic polymorphisms, each with a small contribution to the global risk. In this regard, it must be stressed that although this approach seems wise under the present technological tools available in the clinical laboratory, it is an ever-changing situation as recent history is showing.

From the techniques already available to the routine clinical laboratory, Real-Time-PCR with melting profile analysis seems to be the one that presents the best characteristics in terms of cost, reproducibility, speed, sensitivity and specificity. Its level of automation, and the absence of PCR products handling greatly reduce the human expertise and the laboratory constrains necessary to its implementation. Also, the speed at which each reaction can be performed allows a much higher number of reactions per patient to be performed on the same day, thus increasing the feasibility of multi-locus typing. This can be even easier when machines such as the SmartCycler series (Cepheid, USA) are used, as they allow the simultaneous run of different protocols for the same sample in separate reaction vessels. 
Table 3. Frequency of associated polymorphic risk markers of thrombosis

\begin{tabular}{|c|c|c|c|c|c|}
\hline \multirow[b]{2}{*}{ Genotype/phenotype a) } & \multirow[b]{2}{*}{ \# risk markers ${ }^{b}$} & \multicolumn{3}{|c|}{ \# individuals } & \multirow{2}{*}{$\frac{\text { Significance level }}{\mathrm{AT} / \mathrm{VT}^{\mathrm{c}}}$} \\
\hline & & $\mathrm{C}^{\mathrm{c})}$ & $\mathrm{AT}^{\mathrm{c})}$ & $\mathrm{VT}^{\mathrm{c})}$ & \\
\hline Factor V-Leiden & $\begin{array}{l}\leq 1 \\
>1\end{array}$ & $\begin{array}{c}40 \\
0\end{array}$ & $\begin{array}{c}204 \\
0\end{array}$ & $\begin{array}{c}303 \\
0\end{array}$ & n.s. \\
\hline$+\mathrm{PTH}$ & $\begin{array}{l}\leq 1 \\
>1\end{array}$ & $\begin{array}{c}40 \\
0\end{array}$ & $\begin{array}{c}203 \\
1\end{array}$ & $\begin{array}{c}300 \\
3\end{array}$ & n.s. \\
\hline+ ATIII & $\begin{array}{l}\leq 1 \\
>1\end{array}$ & $\begin{array}{c}40 \\
0\end{array}$ & $\begin{array}{c}203 \\
1\end{array}$ & $\begin{array}{c}300 \\
3\end{array}$ & n.s. \\
\hline + Prot. $\mathrm{C}$ & $\begin{array}{l}\leq 1 \\
>1\end{array}$ & $\begin{array}{c}40 \\
0\end{array}$ & $\begin{array}{c}202 \\
2\end{array}$ & $\begin{array}{c}295 \\
8\end{array}$ & n.s. \\
\hline + Prot. S & $\begin{array}{l}\leq 1 \\
>1\end{array}$ & $\begin{array}{c}40 \\
0\end{array}$ & $\begin{array}{c}200 \\
4\end{array}$ & $\begin{array}{c}289 \\
14\end{array}$ & n.s. \\
\hline + MTHFR & $\begin{array}{l}\leq 1 \\
>1\end{array}$ & $\begin{array}{c}33 \\
7\end{array}$ & $\begin{array}{c}166 \\
38\end{array}$ & $\begin{array}{c}208 \\
95\end{array}$ & 0.0014 \\
\hline
\end{tabular}

a) Factor V leiden, Prothrombin and MTHFR refer to the respective genotypes, whereas ATIII, Prot.C and Proc.S refer to the relative protein levels and are therefore phenotype determinations. Only data of individuals with all genotyping/phenotypic markers tested were included

b) Number of risk markers refers to the total number of risk markers found in each patient when considering only the genotypes/phenotypes from top of the table to each line. Note that for genotype markers each allele was considered one marker, thus an homozygous mutant individual would be considered to have 2 risk markers.

c) AT=Arterial Thrombosis; VT=Venous thrombosis; $\mathrm{C}=$ control

Thus, at present, with the availability of Real-Time-PCR with melting profile analysis, the study should in our opinion include, not only the very strong risk factors such as Factor VLeiden, but also some weaker factors, and common polymorphisms such as Prothrombin G20210A and MTHFR C677T at a minimum. The conjugated study of these factors, not only allows the clarification of the genetic risk of more patients, as allows a clearer stratification of the genetic risk, due to association of several risk factors (12-13). Another complementary approach may be to study, at the protein level, some other genetic risk factors such as Proteins $\mathrm{C}$ and $\mathrm{S}$, Antithrombin III and PAI-1, as these are more difficult to study at the genetic level (due to the nature or number of mutations to be screened).

The results here described do indeed suggest that the conjugation of these strategies allows a clearer elucidation of the genetic risk of each patient, and also a clearer stratification of the genetic risk differences between patients, with potential clinical benefits in terms of differential patient management.

Real-Time-PCR is so far the best of the genotyping techniques available in the clinical molecular biology laboratory. However, this is about to change in the near future, as problems with the miniaturized devices being developed over the last decade are solved, and these devices approach the commercial status, with costs reaching affordable values. Miniaturized devices are being developed for nucleic acid extraction, capillary electrophoresis, PCR, multiplex-PCR, degenerate oligonucleotide primed PCR, Ligase chain reaction, RFLP and hybridisation assays, as well as combinations of these (14-16). Many of these devices are still in an early development stage, and for this reason can only be used in the research setting (16). However, some of these devices have already matured enough to be released commercially, such as the Lab-on-a-chip (Agilent) for capillary electrophoresis and multiple examples of hybridisation chips. For the most part, the major obstacle to the use of these devices in current diagnostic procedures is cost, and this is expected to drop significantly as their use increases, and production and development costs dilute with quantity. Also, as these devices become more widely used, the lab and personel constraints characteristic of any clinical molecular biology lab nowadays are expected to diminish, making these techniques available in most clinical laboratories. Also, as specific devices for disease risk factor genotyping become available, the number of tested risk-factors per patient is also expected to climb (current commercial versions of DNA chips hold up to $20,000-45,000$ probes in a 1.28 $\mathrm{cm} 2$ area [16]), making conclusions on a patient basis clearer, as more of the combined risk factors get tested.

In conclusion, as a fast evolving discipline, clinical molecular genetics is quickly changing, both at the laboratory desk and at the clinical setting. In these changing times, care must be taken to ensure not only adequate testing, but also correct clinical interpretation of the available, but incomplete data. However, as miniaturization proceeds, it is expected that both completeness of the data, as well as reproducibility and standardization at the lab desk results in data easier to obtain and to interpret. 


\section{References}

1. Koeleman BP, Reitsma PH, Allaart CF, Bertina RM: Activated Protein C Resistance as an additional risk factor for thrombosis in protein C-deficient families. Blood 1994; 84:10311035.

2. Ahsen N, Shütz E, Armstrong VW, Oellerich M: Rapid detectiopn of Prothrombotic Mutations of Prothrombin (G20210A), Factor V (G1691A) and Methylenetetrahydrofolate Reductase (C677T) by Real Time Fluorescence PCR with the LightCycler. Clinical Chemistry 1999; 45:694-696

3. Lane DA, Grant P: Role of hemostatic gene polymorphisms in venous and arterial thrombotic disease. Blood 2000; 95:1517-1532.

4. Franco RF, Reitsma P: Genetic risk factors of venous thrombosis. Hum.Genet. 2001; 209:369-384.

5. Franco RF, Reitsma PH: Gene polymorphisms of the haemostatic system and the risk of arterial thrombotic disease. Brit.J.Haematol. 2001; 115:491-506.

6. Chak M, Wallace GR, Graham EM, Stanford MR: Thrombophilia: genetic polymorphisms and their association with retinal vascular occlusive disease. Br.J.Ophtalmol 2001; 85:883-886.

7. Murin S, Marelich GP, Arroliga AC: Hereditary Thrombophilia and venous thromboembolism. Am.J.Respir.Crit.Care Med. 1998; 258:1369-1373.

8. Cabeda J.M: Genética Molecular da Trombose. Mundo Médico 2000; 2:70-71.

9. Wittner C. Rapid Cycle Real-Time PCR: Methods and Apllications in Meuer $S$. Wittwer C., Nakagawara K. (ed): Rapid Cycle Real-Time PCR: Methods and Apllications Berlin, Springer, 2001

10. Bernard PS, Reiser A, Pritham GH. Mutation Detection by Fluorescent Hybridization Probe Melting Curves in Meuer S., Wittwer C. Nakagawara K. (ed): Rapid Cycle Real-Time PCR: Methods and Apllications Berlin, Springer, 2001

11. Landt O. Selection of Hybridization Probes for Real-Time Quantification and Genetic Analysis in Meuer S., Wittwer C. Nakagawara K. (ed): Rapid Cycle Real-Time PCR: Methods and Apllications Berlin, Springer, 2001
12. Nowak-Göttl U, Junker R, Kreuz W, Eckardstein A, Kosch A, Nohe N, Schobess R, Ehrenforth S: Risk of recurrent venous thrombosis in children with combined prothrombotic risk factors. Blood 2001; 97:858-862.

13. Salomon O, Steinberg DM, Zivelin A, Gitel S, Dardik R, Rosenberg N, Berliner S, Inbal A, Many A, Lubetsky A, Varon D, Martinowitz U, Seligsohn U: Single and combined prothrombotic factors in patients with idiopathic venous thromboembolism: prevalence and risk assessment. Arterioscler.Thromb.Vasc.Biol. 1999; 19:511-518.

14. Kricka LJ: Miniaturization of analytical systems. Clinical Chemistry 1998; 44:2008-2014.

15. Munro NJ., Snow K, Kant JA, Landers JP: Molecular Diagnostics on Microfabricated Electrophoretic devices: from slab gel- to capillary- to Microchip-based assays for T- and Bcell lymphoprolipherative disorders. Clinical Chemistry 1999; 45:1906-1917.

16. McGlennen RC.: Miniaturization technologies for molecular diagnostics. Clinical Chemistry 2001; 47:393-402. 